\title{
Skill-biased export growth: accounting for the changes in labor contents across ethnic groups in Malaysia (1991-2000)
}

\begin{abstract}
This paper quantifies the extent to which trade liberalization in Malaysia between 1991 and 2000 has contributed to the expansion in the most skilled labor, which in turn can validate the trade-enhanced quality upgrading hypothesis. By using an input-output structural decomposition analysis (SDA), results confirm the theoretical predication that skills help to upgrade the quality of exporting commodities, by documenting that trade growth is associated with increases in the use of the higher skilled labor. We observe that Chinese and Indian ethnic groups contribute the most to the quality upgrading of exporting commodities, more so than the Malays, which imply productivity differentials among the ethnic groups.
\end{abstract}

Keyword: Labour content; Structural decomposition analysis (SDA); Ethnic groups 